\title{
Early Transcriptional Changes Induced by Wnt/ $\beta$-Catenin Signaling in Hippocampal Neurons
}

\author{
Eduardo Pérez-Palma, Víctor Andrade, Mario O. Caracci, Bernabé I. Bustos, \\ Camilo Villaman, Matías A. Medina, Miguel E. Ávila, Giorgia D. Ugarte, \\ and Giancarlo V. De Ferrari
}

Centro de Investigaciones Biomédicas (CIB), Facultad de Ciencias Biológicas y Facultad de Medicina, Universidad Andres Bello, Santiago, Chile

Correspondence should be addressed to Giancarlo V. De Ferrari; gdeferrari@unab.cl

Received 5 August 2016; Revised 20 October 2016; Accepted 27 November 2016

Academic Editor: Franscisco Gomez-Scholl

Copyright (C) 2016 Eduardo Pérez-Palma et al. This is an open access article distributed under the Creative Commons Attribution License, which permits unrestricted use, distribution, and reproduction in any medium, provided the original work is properly cited.

\begin{abstract}
Wnt $/ \beta$-catenin signaling modulates brain development and function and its deregulation underlies pathological changes occurring in neurodegenerative and neurodevelopmental disorders. Since one of the main effects of Wnt $/ \beta$-catenin signaling is the modulation of target genes, in the present work we examined global transcriptional changes induced by short-term Wnt3a treatment $(4 \mathrm{~h})$ in primary cultures of rat hippocampal neurons. RNAseq experiments allowed the identification of 170 differentially expressed genes, including known Wnt/ $\beta$-catenin target genes such as Notum, Axin2, and Lef1, as well as novel potential candidates Fam84a, Stk32a, and Itga9. Main biological processes enriched with differentially expressed genes included neural precursor (GO:0061364, $p$-adjusted $\left.=2.5 \times 10^{-7}\right)$, forebrain development (GO:0030900, $p$-adjusted $\left.=7.3 \times 10^{-7}\right)$, and stem cell differentiation (GO:0048863 $p$-adjusted $\left.=7.3 \times 10^{-7}\right)$. Likewise, following activation of the signaling cascade, the expression of a significant number of genes with transcription factor activity (GO:0043565, $p$-adjusted $\left.=4.1 \times 10^{-6}\right)$ was induced. We also studied molecular networks enriched upon Wnt3a activation and detected three highly significant expression modules involved in glycerolipid metabolic process (GO:0046486, $p$-adjusted $\left.=4.5 \times 10^{-19}\right)$, learning or memory $\left(\mathrm{GO}: 0007611\right.$, $p$-adjusted $\left.=4.0 \times 10^{-5}\right)$, and neurotransmitter secretion $(\mathrm{GO}: 0007269$, $p$-adjusted $=5.3 \times 10^{-12}$ ). Our results indicate that $\mathrm{Wnt} / \beta$-catenin mediated transcription controls multiple biological processes related to neuronal structure and activity that are affected in synaptic dysfunction disorders.
\end{abstract}

\section{Introduction}

The Wnt signaling cascade plays an essential role during embryogenesis and adult tissue homeostasis. Wnts are lipid modified secreted glycoproteins that signal through three major cellular pathways: the Planar Cell Polarity, the $\mathrm{Wnt} / \mathrm{Ca}^{2+}$, and the Wnt $/ \beta$-catenin signaling pathway, also referred to as the canonical Wnt signaling pathway [1-3]. The canonical cascade initiates with the binding of a Wnt ligand to Frizzled (FZD) receptors and LRP5/6 coreceptors located at the cellular membrane [4]. Wnt binding leads to the inhibition of the $\beta$-catenin destruction complex consisting of Axin, adenomatous polyposis coli (APC) [5], casein kinase 1 (CK1), and glycogen synthase kinase $3 \beta$ (GSK3 $\beta$ ) [6], which ultimately results in the stabilization of $\beta$-catenin protein in the cytosol and its subsequent nuclear translocation where it interacts with members of the T-cell factor/lymphoid enhancing factor (TCF/LEF) family of transcription factors to enhance transcription of Wnt/ $\beta$-catenin target genes [3]. Conversely, in the absence of Wnt ligand activation, Axin and APC facilitate the sequential phosphorylation of $\beta$-catenin by $\mathrm{CK} 1$ and GSK3 $\beta$ [6] tagging this protein for ubiquitination and subsequent proteasome mediated degradation [7].

Throughout mammalian brain development the activity of the Wnt cascade is spatially confined to specialized regions such as the olfactory bulb, frontal cortex, hippocampal formation, and the cerebellum [8-11]. In these brain domains Wnt $/ \beta$-catenin signaling participates in diverse biological processes including neurogenesis [12], axonal remodeling and patterning $[13,14]$, and development and maturation of 
functional synapses within the CNS [15-20]. Indeed, Wnt1, Wnt3a, Wnt7a, and Wnt8 are ligands known to activate $\mathrm{Wnt} / \beta$-catenin signaling and are involved in brain development and synaptogenesis $[21,22]$. Wnt3a is essential in early development of hippocampal structures and participates in the establishment of long term potentiation events [23, 24]. Wnt7a and Wnt8a have also been shown to regulate excitatory synaptic formation $[17,25]$. Furthermore a recent study suggests that LRP6, Wnt/ $\beta$-catenin signaling coreceptor, is critical for the development of functional synapses in vivo [25]. Therefore, given its multiple roles in synaptic function and brain homeostasis, Wnt $/ \beta$-catenin signaling is a functional and positional candidate to understand complex prevalent neurological conditions in the human population.

At the presynaptic region, canonical Wnt ligands such as Wnt7a and Wnt3a enhance the clustering and recycling of synaptic vesicles (SVs) in primary cultures of rat hippocampal neurons [26]. Consistently, loss of Wnt7a function inhibits SVs clustering, an effect that is mimicked by lossof-function of Dishevelled 1 (DVL1) signaling downstream of Wnt ligands [19]. Interestingly, the Wnt7a/Dvll double mutant shows defects in spine morphogenesis and excitatory synaptic neurotransmission [17], which parallels behavioral abnormalities with a disrupted presynaptic assembly and excitatory/inhibitory balance. Wnt/ $\beta$-catenin signaling also seems to trigger neurotransmitter release and SV trafficking by modulating SV-associated phosphoproteins. While Wnt7a and Wnt3a enhance the clustering [27] and phosphorylation [28] of synapsin 1 at the synaptic button prior to neurotransmitter release, Dvll is involved in neurotransmitter release through direct binding to synaptotagmin I in differentiated neurons [29].

Experience driven plasticity is highly dependent on proper synaptic transmission and is mainly modulated by $\mathrm{Ca}^{2+}$ related pathways. In this regard, Wnt noncanonical and canonical pathways have been extensively related to $\mathrm{Ca}^{2+}$ homeostasis and signaling $[19,28,30,31]$. For instance, ligands such as Wnt3a [28], Wnt5a [30], and Wnt7a [19] have all been shown to increase $\mathrm{Ca}^{2+}$ influxes to stimulate excitatory synaptic strength in hippocampal neurons or in peripheral nerves to alter pain sensitivity [32]. Other mechanisms modulating the activity of the synaptic terminal involve the function of cell adhesion proteins, most notably transsynaptic cadherin- $\beta$-catenin interactions that have an essential function during the recruitment and clustering of SVs to synapses [33-37]. Importantly, the effect on synaptic function, plus the biological control of neuronal polarity and axon outgrowth/navigation to their final synaptic targets, is mainly accomplished through rapid posttranslational changes affecting the cytoskeletal machinery $[38,39]$.

While Wnt $/ \beta$-catenin ligands have a profound effect on the modulation of synaptic terminals; however the transcriptional program elicited by the signaling cascade in neurons has received little attention. Therefore, given that the integration of differentially expressed genes into biological networks provides a wider vision for the transcriptional landscape of a particular cell-type and considering that others and we have previously observed that $\mathrm{Wnt} / \beta$-catenin target gene expression is rapidly induced $(2-6 \mathrm{~h})$ upon activation of the signaling cascade [40-44], here we use genomewide transcriptional data to identify target genes and main biological processes directed by transient Wnt3a exposure $(4 \mathrm{~h})$ in primary cultures of rat hippocampal neurons. We expect that understanding of the genetic program maintained by $\beta$-catenin/TCF-LEF complexes in hippocampal cells will provide molecular mechanisms to couple activity, structure, and function of synaptic networks and circuits in this important brain region, which is severely affected in neurodegenerative and neurodevelopmental disorders.

\section{Materials and Methods}

2.1. Primary Cultures of Rat Hippocampal Neurons. Hippocampal neurons were dissociated and maintained as described before [28]. Briefly, neurons were taken from 18day pregnant Sprague-Dawley rats and maintained for 14 days in vitro (DIV) on 12-well culture plates $(500,000$ cells/well) coated with poly-L-lysine (Sigma) and supplemented with neurobasal/B27 media (Gibco). The culture was placed on a shelf in a $37^{\circ} \mathrm{C}$ humidified $\mathrm{CO}_{2}$ incubator, and the medium was changed every 2 days.

2.2. Wnt3a Purification. Wnt3a is a specific Wnt/ $\beta$-catenin signaling agonist that can be efficiently recovered from conditioned medium from Wnt3a-secreting L-cells (ATCC, Rockville, MD; see also the Wnt homepage at http://web.stanford.edu/group/nusselab/cgi-bin/wnt/). Wnt3a purification was carried out as previously described [28, 57, 58]. The presence of the Wnt3a protein was detected with an antiWnt3a antibody (R \& D Systems, Minneapolis, MN). Purity was analyzed by SDS-PAGE (8\%), stained with Coomassie Blue G250, and analyzed through densitometry by using software ImageJ [59].

2.3. RNAseq Experiments. Rat hippocampal neurons were transiently exposed with Wnt3a for $4 \mathrm{~h}$ and then total RNA was extracted ( 3 control and 3 Wnt 3 a samples matched by experiment). RNA integrity was assessed using an Agilent 2100 Bioanalyzer (Agilent Technologies, Santa Clara, CA, USA). RNA integrity numbers (RIN) obtained were above 7.5 and suitable for sequencing. RNA was processed using the Illumina TruSeq Stranded mRNA kit to generate $280 \mathrm{bp}$ size paired-end libraries. Libraries were sequenced using the Illumina HiSeq 2000 benchtop sequencer. Raw reads (average depth of $100.62 \mathrm{M} 2 \times 80$ ) were aligned to the Rnor6 build for rat genome reference, using Bioconductor R Package (v3.1; [60]). Differential expression was statistically analyzed with DESeq v1.20 following author recommendations [61]. Heterogeneity across the samples was examined visualizing reads distribution plots before and after DESeq normalization. Pearson's correlation analysis showed $r 2$ values above 0.93 between all samples, within the standards (i.e., 0.92 and 0.98) suggested by ENCODE [62]. The complete pipeline of our study is presented in Supplementary Figure 1 in Supplementary Material available online at http://dx.doi.org/10.1155/2016/4672841. Summary statistics for the sequencing process and alignment are provided in 
Supplementary Tables 1 and 2, respectively. Likewise, read normalization results are presented in Supplementary Figure 2.

2.4. Gene Ontology (GO) Enrichment Analysis. We tested the gene ontology (GO; http://geneontology.org/) [63] structure and annotations using the package Ontologizer [64], considering categories with less than 500 members to avoid associations to major categories that are less informative (i.e., signaling) and excluding the ones "Inferred by Electronic Annotation" (IEA), from "Reviewed Computational Analysis" (RCA) and with "No biological Data available" (ND), which are characterized by a high rate of false positives [65, 66]. We used the parent-child-union algorithm to call for overrepresentation adjusting the $p$ values with BenjaminiHochberg multiple testing correction, to avoid false positives [67]. We considered GO terms significantly overrepresented with an adjusted $p$ value below $1 \times 10^{-6}$ for further analyses.

2.5. Functional Protein Association Network (FPAN). To assay for known interactions between the differentially expressed genes we retrieved high confidence functional interactions from the STRING 10.0 database (search tool for the retrieval of interacting genes/proteins; http://string-db.org/) [68] which contains curated interactions from different evidence sources (i.e., genomic context, coexpression, and curated literature). We kept only "highest confidence" interactions (i.e., the interactions with a combined score $>0.9$ provided by STRING). The final FPAN was composed of 9,443 nodes (rat genes) and 309,728 nonredundant edges (interactions). All network and subnetworks were visualized with Cytoscape software [69].

2.6. Module Search. All gene-wise $p$ values obtained with DESeq were introduced in to the FPAN as a floating-point attribute. A fold change greater than $1.25(25 \%)$ was used as a threshold for inclusion ( $n=2,892$ genes). Module search was carried out with the Cytoscape JActiveModules plugin [70] with a gene overlap threshold of $20 \%$ following the method reported previously $[66,71]$. Briefly, the program searches for significant highly connected subnetworks or modules enriched with expression information ( $p$ value). Starting from one random node (Monte Carlo procedure) modules grow in comparison with an expected background distribution created by the software from 10,000 internal randomizations, obtaining a specific standard deviation score ( $S$ score). Modules with $S>3$ (3 standard deviation above the mean of randomized scores) and with a gene number between 10 and 50 were considered significant [72]. To acquire a mean $S$ score and standard deviation (SD) for each resulting module the search was performed 10 times. Finally, the same procedure was conducted with permuted $p$ values over the entire genes present in the FPAN (permuted analysis). Statistical differences between permuted and real (Wnt3a) analyses were assessed through one-sided Student's $t$-test.
TABLE 1: Top 20 nominal significant Wnt3a-upregulated genes in hippocampal neurons.

\begin{tabular}{lcccc}
\hline Symbol ID & FC & $p$ value & Wnt pathway & References \\
\hline Fam84a & 2.4 & $2.2 \times 10^{-6}$ & - & - \\
Notum & 14.1 & $1.5 \times 10^{-5}$ & Wnt target gene & {$[45]$} \\
Lef1 & 2.1 & $1.7 \times 10^{-5}$ & Wnt target gene & {$[46]$} \\
Axin2 & 3.5 & $1.2 \times 10^{-4}$ & Wnt target gene & {$[47]$} \\
Prkg2 & 2.7 & $1.4 \times 10^{-4}$ & Functional & {$[48]$} \\
Cxcl3 & 4.6 & $5.2 \times 10^{-4}$ & Wnt target gene & {$[49]$} \\
Ahr & 2.1 & $1.0 \times 10^{-3}$ & Wnt target gene & {$[50]$} \\
Stk32a & 1.8 & $1.3 \times 10^{-3}$ & - & - \\
Itga9 & 2.0 & $1.7 \times 10^{-3}$ & - & - \\
Tnfresf19 & 2.4 & $1.8 \times 10^{-3}$ & Wnt target gene & {$[51]$} \\
Tmem72 & 1.7 & $2.0 \times 10^{-3}$ & - & - \\
Fras1 & 1.9 & $2.2 \times 10^{-3}$ & - & - \\
Fam167a & 1.8 & $2.2 \times 10^{-3}$ & - & - \\
Gata2 & 2.8 & $2.3 \times 10^{-3}$ & Wnt target gene & {$[52]$} \\
Id2 & 1.3 & $3.0 \times 10^{-3}$ & Wnt target gene & {$[53]$} \\
Msx2 & 2.1 & $3.9 \times 10^{-3}$ & Wnt target gene & {$[54]$} \\
Sp5 & 10.3 & $4.2 \times 10^{-3}$ & Wnt target gene & {$[55]$} \\
Cd83 & 2.1 & $4.4 \times 10^{-3}$ & - & - \\
Cgnl1 & 1.5 & $4.9 \times 10^{-3}$ & - & - \\
Hunk & 1.5 & $5.3 \times 10^{-3}$ & Wnt target gene & {$[56]$} \\
\hline
\end{tabular}

Functional: known to modulate Wnt pathway transcriptional activity. FC: fold change.

\section{Results}

3.1. Differentially Expressed Wnt/ $\beta$-Catenin Target Genes and Ontological Categories. To observe a direct transcriptional effect of $\mathrm{Wnt} / \beta$-catenin signaling in primary cultures of hippocampal neurons and thus avoid noise due to activation of secondary unrelated pathways [40-44], we compared the whole transcriptome of cells transiently incubated with purified Wnt3a ( $4 \mathrm{~h}, n=3)$ with cells from the same batch under control conditions (Wnt3a vehicle; $n=3$; see Material and Methods). We identified 170 differentially expressed genes with a nominal $p$ value of $<0.05$ (Figure 1). Raw read counts per sample, in ascending order according to their respective fold change (FC), are shown in Figures 1 (a) and 1(b). Smear plots between treatment and control conditions revealed that differentially expressed genes (red dots) displayed an inverse relationship between the observed FC and the mean of normalized counts (Figure 1(c)). Overall, we found that $1 \%$ of the total rat genes included in our analyses (170 out of 16,252; Figure 1(d)) showed a differential response upon Wnt3a stimulation and that $88 \%$ of these genes were upregulated (149 genes) (Supplementary Table 3). Functional characterization of differentially expressed genes revealed that transcription factors (18.1\%), proteins with nucleic acid binding activity (14.8\%), and signaling related molecules $(8.7 \%)$ represent main protein categories activated upon Wnt3a stimulation (Figure 1(e)).

We observed that the strongest upregulated gene in Wnt3a treated neurons was Fam84a (Gene ID: 313969; nominal $p$ value $=2.2 \times 10^{-6} ; \mathrm{FC}=2.4$; Table 1). Likewise, 


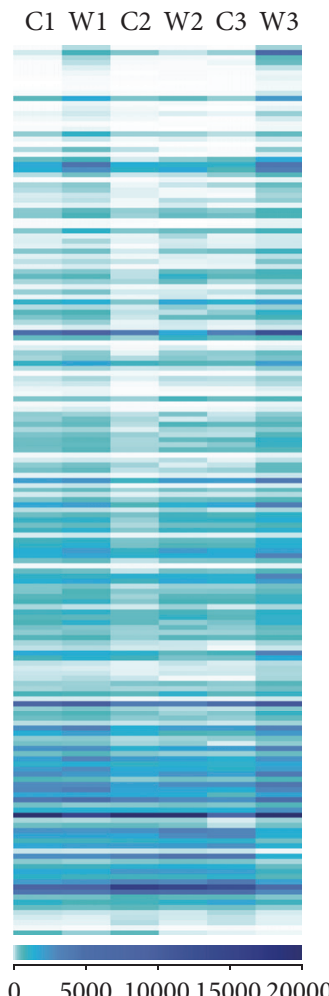

(a)

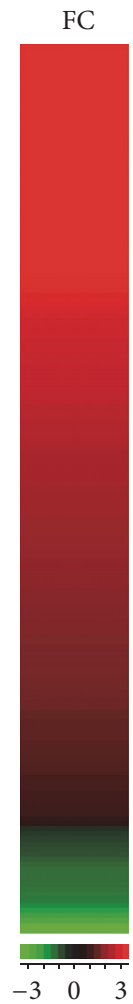

(b)

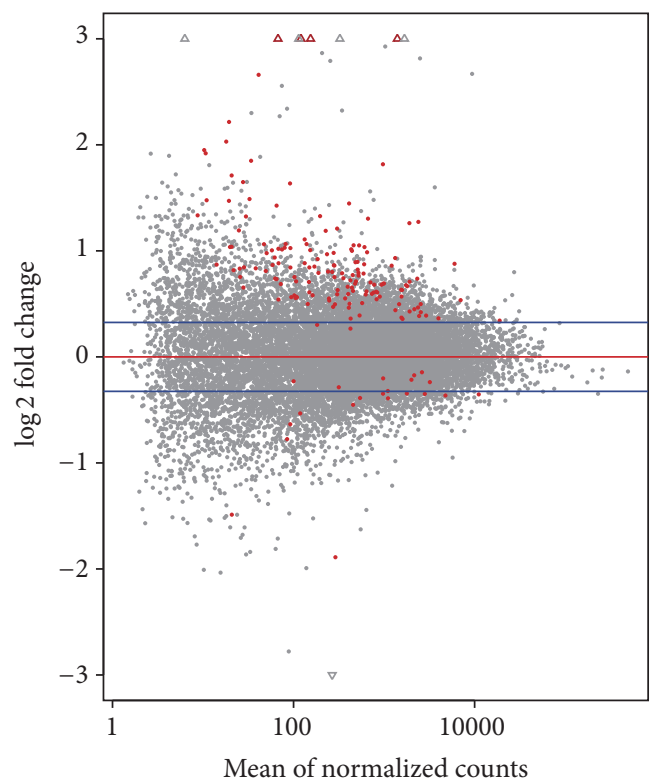

(c)
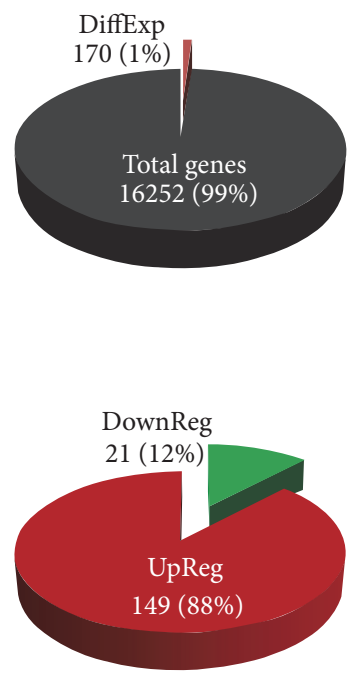

(d)

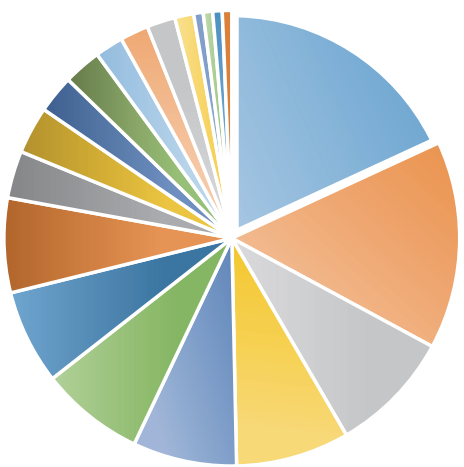

Transcription factor (18.1\%)

- Nucleic acid binding (14.8\%)

- Signaling molecule (8.7\%)

- Transferase (8.1\%)

- Enzyme modulator (7.4\%)

- Hydrolase (7.4\%)

- Receptor (6.7\%)

Transporter (6.7\%)

- Cytoskeletal protein (3.4\%)

Extracellular matrix protein (3.4\%)

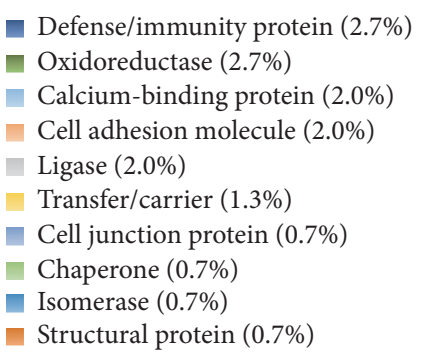

(e)

FIGURE 1: Transcriptome analysis, differentially expressed genes, and their functional classification. (a) Rat genes total amount of raw reads is displayed for each of the samples sequenced (C1: Control 1, W1: Wnt1, C2: Control 2, W2: Wnt2, C3: Control 3, and W3: Wnt3). Dark to light blue color scale denotes a higher to lower number of counts per gene, respectively. (b) Fold change observed for the cluster analysis of the 170 differentially expressed rat genes in red to green scale for up- to downregulation, respectively. (c) Smear plot. $\log 2$ fold change ( $y$ axis) values versus normalized read counts per gene ( $x$ axis) between treatment and control conditions. A total of 170 confident transcript calls over the threshold of $0.05 p$ value (red dots) are shown. (d) Comparison of the 170 genes found differentially expressed and the total genes analyzed. (e) For all genes over threshold, we determined their protein class with the Panther software (v11.0). 
TABLE 2: GO categories overrepresented in the 170 differentially expressed genes.

\begin{tabular}{lllccc}
\hline Category & GO ID & GO Name & GIP & GIS & $p$-adjusted (BH) \\
\hline & GO:0061351 & Neural precursor cell proliferation & 122 & 14 & $1.6 \times 10^{-10}$ \\
& GO:0030900 & Forebrain development & 266 & 18 & $2.2 \times 10^{-09}$ \\
& GO:0048863 & Stem cell differentiation & 267 & 18 & $2.3 \times 10^{-09}$ \\
BP & GO:0007420 & Brain development & 418 & 22 & $1.0 \times 10^{-06}$ \\
& GO:0048732 & Gland development & 289 & 18 & $1.6 \times 10^{-06}$ \\
& GO:0048864 & Stem cell development & 58 & 9 & $1.6 \times 10^{-06}$ \\
& GO:0021872 & Forebrain generation of neurons & 138 & 12 & $3.3 \times 10^{-06}$ \\
& GO:0021953 & Central nervous system neuron differentiation & 173 & 13 & $9.6 \times 10^{-06}$ \\
MF & GO:0045165 & Cell fate commitment & 452 & 22 & $4.1 \times 10^{-06}$ \\
\hline
\end{tabular}

BP: biological processes; CC: cellular components; MF: molecular function; GO ID: gene ontology term ID; GIP: genes in population; GIS: genes in study; BH: Benjamini-Hochberg correction multiple testing correction.

among the top 20 upregulated genes we found $11 \mathrm{Wnt} / \beta$ catenin target genes (Table 1 and Supplementary Table 3), including the palmitoleoyl-protein carboxylesterase Notum (ID: 303743 ; nominal $p$ value $=1.5 \times 10^{-5} ; \mathrm{FC}=14.1$ ), Lef1 (ID: 161452 ; nominal $p$ value $=1.7 \times 10^{-5} ; \mathrm{FC}=2.1$ ), Axin2 (ID: 29134; nominal $p$ value $=1.2 \times 10^{-4} ; \mathrm{FC}=3.5$ ), and the chemokine (C-X-C motif) ligand $3 \mathrm{Cxcl} 3$ (ID: 171551; nominal $p$ value $\left.=5.2 \times 10^{-4} ; \mathrm{FC}=4.6\right)$. Interestingly, novel Wnt $/ \beta$-catenin targets genes ranked between known targets and included the serine/threonine kinase 32A Stk32a (ID: 364858; nominal $p$ value $=1.3 \times 10^{-3} ; \mathrm{FC}=1.8$ ), the integrin subunit alpha 9 Itga9 (ID: 586004; nominal $p$ value $\left.=1.7 \times 10^{-3} ; \mathrm{FC}=2.0\right)$, and the transmembrane protein 72 TMEM72 (ID: 362424 ; nominal $p$ value $=2.0 \times$ $10^{-3} ; \mathrm{FC}=1.7$ ), among others (Table 1 ). These results indicate that after transient treatment with Wnt3a we can readily identify nascent RNA messages derived from activating the transcriptional program controlled by Wnt $/ \beta$-catenin signaling in these hippocampal neurons. As to noncanonical Wnt signaling components being expressed in primary neurons as a consequence of Wnt3a treatment, we intersected the 170 nominally differentially expressed genes with the reactome pathway "beta catenin independent Wnt signaling" including 143 genes belonging to PCP and/or $\mathrm{Ca}^{2+}$ noncanonical pathways (DOI: 10.3180/REACT_172694.1). Only Lef1, Tcf7, and Prkg2 were found in both gene sets (Supplementary Figure 3a). While Lef1 and Tcf7 are widely acknowledged as major canonical components, Prkg2 is recognized only as a functional modulator of the canonical pathway (Table 2) through the inhibition of GSK3 $\beta$ activity [48]. Thus we conclude that Wnt3a did not enhance the expression of noncanonical components.

At a global level, we found that differentially expressed genes after Wnt3a treatment define gene ontology (GO) categories that have essential roles during brain development and homeostasis (Table 2). We observed that major biological process (BP) categories enriched with differentially expressed genes included neural precursor cell proliferation (GO:0061351; adjusted $p$ value $=1.6 \times 10^{-10}$ ), forebrain development (GO:0030900; adjusted $p$ value $=2.2 \times 10^{-9}$ ), and stem cell differentiation (GO:0048863; adjusted $p$ value $\left.=2.3 \times 10^{-9}\right)$. Similarly, sequence-specific DNA binding activity (GO:0043565; adjusted $p$ value $=4.1 \times 10^{-6}$ ) was the main molecular function (MF) category overrepresented in our analysis. All 170 differential expressed genes and their functional relationships are shown in Figure 2. A high degree of overlap was observed between previous GO terms with 37 genes ( 7 of which were among top 20 upregulated; Figure 2, hexagonal nodes) responsible for the enrichment given by 89 ontological associations (Figure 2, color edges). Additionally, we detected 11 high confidence interactions connecting 21 out of the 170 genes using the entire rat functional protein association network (FPAN) extracted from STRING database (see Materials and Methods).

3.2. Molecular Interaction Networks Activated by Wnt/ $\beta$ Catenin Signaling. While differential gene expression analysis allows for the identification of disease altered genes in specific tissues by analyzing one gene at the time, this approach does not take into account the functional relationships between genes [73]. Therefore, since the convergence or aggregation of additional expression signals in a set of genes can become significant in a network context, we searched for highly connected subnetworks or modules displaying significant changes in expression upon Wnt signaling activation. We performed a module search using 2,892 upregulated genes (DESeq FC > 1.25) on the entire rat FPAN composed of a total of 9,443 genes with at least 1 high confidence interaction defined by STRING database (edge score above 900, see Materials and Methods) [68]. We observed a significantly higher number of modules $(p$ value $=5.00 \times 10^{-4}$ ) using actual Wnt3a transcriptomic data (average $=17.00 ; \mathrm{SD}=0.982$ ) in comparison with modules arising from chance using permuted data (average $=$ $11.00, \mathrm{SD}=0.987$ ) (Figure 3(a)). While the average score of the first fourth modules derived from Wnt3a data was significantly higher compared to their permuted counterpart (M1-M4; Figure 3(b)), the average score for M4 was below the highest random score and therefore M4 was not considered for further analysis. Altogether, these results show that the number and structure of modules remained consistent across iterations and that they could not be reached by chance, 


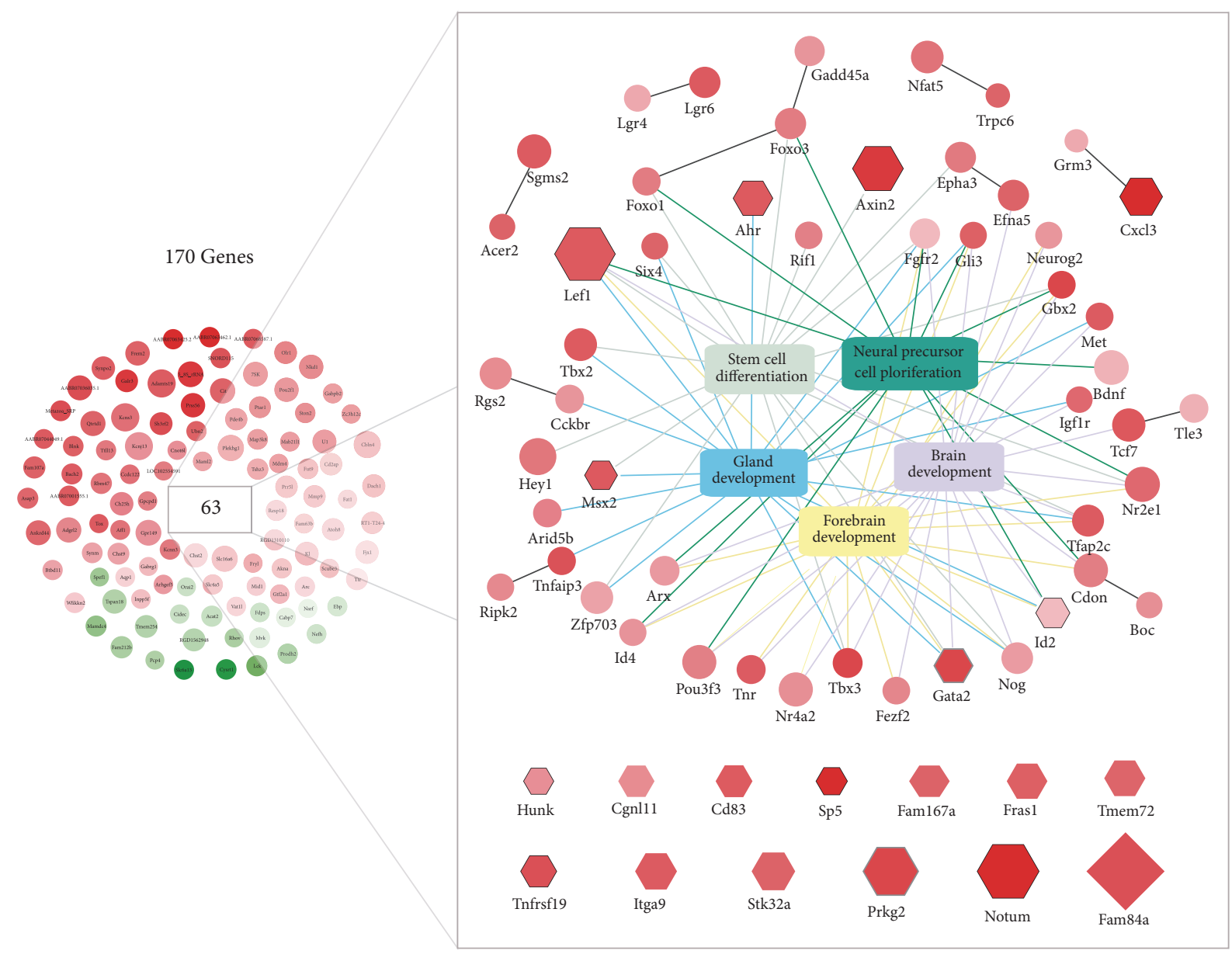

FIGURE 2: Functional relationships of Wnt differentially expressed genes. Nominal Wnt-induced differentially expressed genes are presented ( $n=170)$ alongside their mayor functional interactions. Node color represents the observed fold change (FC) upon Wnt3a treatment in a gradient from green (downregulation) to red (upregulation) values (i.e., green: FC $<1$; red FC $>1$; white: FC $=1$ ). Similarly, node size is proportional to the $-\log 10 p$ value assigned by DESeq to the gene. Central boxes denote the top 5 overrepresented GO categories and their respective gene associations (color edges) which are presented for neural precursor (GO:0061364), forebrain development (GO:0030900), stem cell differentiation (GO:0048863), brain development (GO:0007420), and gland development (GO:0048732) categories. Direct functional interactions extracted from STRING are shown with black edges. Hexagon-shaped nodes show top 25 genes differentially expressed. Diamond-shaped node highlight top 1 differentially expressed gene (Fam68a). Black and grey node borders denote top 20 Wnt target or functional evidence, respectively.

supporting the idea that Wnt3a-derived subnetworks M1, M2, and $\mathrm{M} 3$ are indeed biologically meaningful. Components and interactions of M1, M2, and M3 subnetworks are provided in Figure 4. GO analysis further revealed that M1 was highly enriched with genes belonging to the glycerolipid metabolic process category (Table 3; GO:0046486; adjusted $p$ value $=$ $4.5 \times 10^{-19}$ ) and with lipase activity (GO:0016298; adjusted $p$ value $\left.=5.2 \times 10^{-9}\right) ;$ M2 was mainly involved in learning or memory processes (Table 3; GO:0007611; adjusted $p$ value $=4.0 \times 10^{-5}$ ) with genes related to cell adhesion molecule binding activity (GO:0050839; adjusted $p$ value $=1.1 \times$ $10^{-6}$ ); and M3 was overrepresented with genes belonging to neurotransmitter secretion process (Table 3; GO:0007269; adjusted $p$ value $\left.=5.3 \times 10^{-12}\right)$ and with syntaxin-1 binding activity (GO:0017075; adjusted $p$ value $=1.2 \times 10^{-12}$ ). The complete list of the 93 genes belonging to M1, M2, and M3 subnetworks is presented in Supplementary Table 4 with their observed FC and $p$ value.

\section{Discussion}

The transcriptional program directed by Wnt $/ \beta$-catenin signaling has been examined mainly in cancer models and has allowed for the identification of novel target genes and a better understanding of the oncogenic properties of this pathway [74-76]. Conversely, much remains to be elucidated about the transcriptional program of the cascade in the central nervous system. In this context, initial attempts to discover novel Wnt/ $\beta$-catenin target genes functioning in the brain relied on in silico analyses of proximal gene promoters enriched with TCF/LEF binding sites $[77,78]$. More recently, bioinformatics and transcriptomic approaches have been 


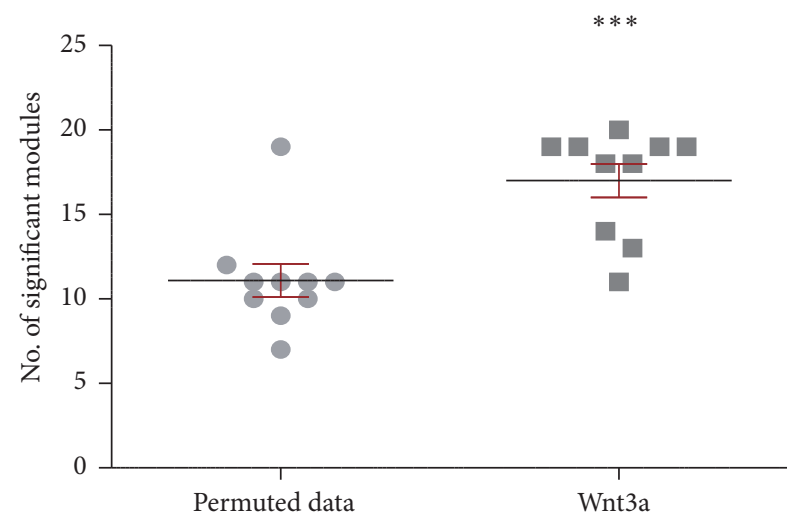

(a)

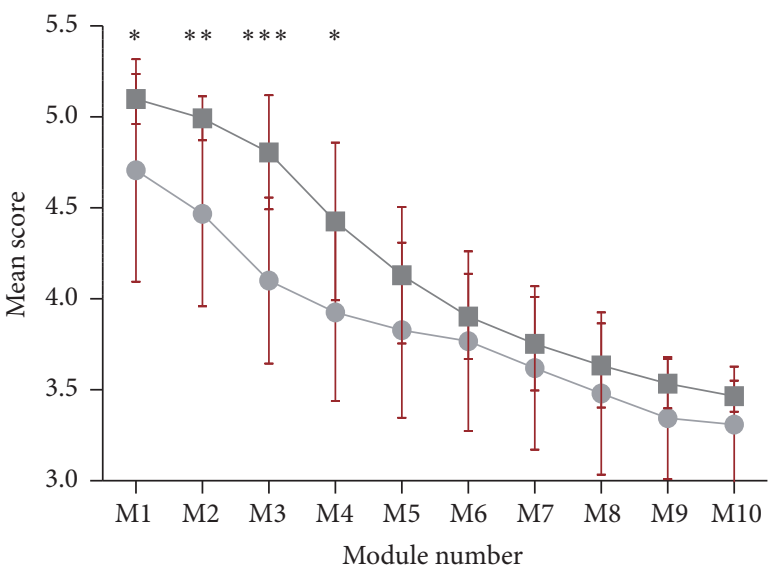

(b)

FIGURE 3: Module search results over the rat FPAN. (a) The number of significant modules (size between 10 and 50 genes with a SD score $>3$ ) obtained with nominal data (Wnt3a, dark grey) and with the same values permuted across the FPAN (permuted data, light grey). (b) Individual SD score comparison of the top 10 modules obtained in the corresponding module searches presented in (a). Asterisk denotes the Student $t$-test $p$ value significance $\left({ }^{*} p<0.05 ;{ }^{* *} p<0.001 ;{ }^{* * *} p<0.0001\right)$.

TABLE 3: Top 3 GO categories overrepresented in Wnt3a-induced M1, M2, and M3 subnetworks.

\begin{tabular}{|c|c|c|c|c|c|c|}
\hline Module & Category & GO ID & GO Name & GIP & GIS & $p$-adjusted (BH) \\
\hline \multirow{6}{*}{ M1 } & \multirow{3}{*}{$\mathrm{BP}$} & GO:0046486 & Glycerolipid metabolic process & 193 & 18 & $4.5 \times 10^{-19}$ \\
\hline & & GO:0006644 & Phospholipid metabolic process & 166 & 17 & $1.1 \times 10^{-18}$ \\
\hline & & GO:0006650 & Glycerophospholipid metabolic process & 134 & 16 & $1.2 \times 10^{-18}$ \\
\hline & \multirow{3}{*}{ MF } & GO:0016298 & Lipase activity & 59 & 8 & $5.2 \times 10^{-09}$ \\
\hline & & GO:0016788 & Hydrolase activity, acting on ester bonds & 430 & 14 & $1.2 \times 10^{-08}$ \\
\hline & & GO:0004620 & Phospholipase activity & 47 & 7 & $1.7 \times 10^{-08}$ \\
\hline \multirow{8}{*}{ M2 } & \multirow{2}{*}{$\mathrm{BP}$} & GO:0007611 & Learning or memory & 181 & 7 & $4.0 \times 10^{-05}$ \\
\hline & & GO:0050890 & Cognition & 200 & 7 & $4.4 \times 10^{-05}$ \\
\hline & \multirow{3}{*}{$\mathrm{CC}$} & GO:0043256 & Laminin complex & 8 & 4 & $2.0 \times 10^{-07}$ \\
\hline & & GO:0005610 & Laminin-5 complex & 4 & 3 & $2.9 \times 10^{-06}$ \\
\hline & & GO:0005605 & Basal lamina & 18 & 4 & $2.9 \times 10^{-06}$ \\
\hline & \multirow{3}{*}{ MF } & GO:0050839 & Cell adhesion molecule binding & 131 & 7 & $1.1 \times 10^{-06}$ \\
\hline & & GO:0001948 & Glycoprotein binding & 74 & 5 & $1.7 \times 10^{-05}$ \\
\hline & & GO:0005178 & Integrin binding & 76 & 5 & $1.7 \times 10^{-05}$ \\
\hline \multirow{9}{*}{ M3 } & \multirow{3}{*}{$\mathrm{BP}$} & GO:0007269 & Neurotransmitter secretion & 82 & 10 & $5.3 \times 10^{-12}$ \\
\hline & & GO:0006887 & Exocytosis & 176 & 12 & $5.3 \times 10^{-12}$ \\
\hline & & GO:0016079 & Synaptic vesicle exocytosis & 37 & 8 & $1.2 \times 10^{-11}$ \\
\hline & \multirow{3}{*}{$\mathrm{CC}$} & GO:0044456 & Synapse part & 373 & 14 & $2.6 \times 10^{-11}$ \\
\hline & & GO:0043679 & Axon terminus & 131 & 10 & $7.7 \times 10^{-11}$ \\
\hline & & GO:0044306 & Neuron projection terminus & 139 & 10 & $9.4 \times 10^{-11}$ \\
\hline & \multirow{3}{*}{ MF } & GO:0017075 & Syntaxin-1 binding & 16 & 7 & $1.2 \times 10^{-12}$ \\
\hline & & GO:0000149 & SNARE binding & 69 & 8 & $8.0 \times 10^{-10}$ \\
\hline & & GO:0019905 & Syntaxin binding & 46 & 7 & $1.7 \times 10^{-09}$ \\
\hline
\end{tabular}

BP: biological processes; CC: cellular components; MF: molecular function; GO ID: gene ontology term ID; GIP: genes in population; GIS: genes in study; BH: Benjamini-Hochberg correction multiple testing correction.

used in thalamic neurons [79], or human neural progenitor cells [41], to identify Wnt/ $\beta$-catenin target genes involved in neuronal excitation or neurodegenerative diseases, including Alzheimer's disease. In this regard, multiple lines of evidence support a functional role for $\mathrm{Wnt} / \beta$-catenin signaling in prevalent neurological disorders related to synaptic dysfunction including autism, Alzheimer's disease, or epilepsy [8083]. Nevertheless, although these studies have resulted in hundreds of potential novel candidates, the expression of those target genes shows minimal overlap (less than $2 \%$ ) in 


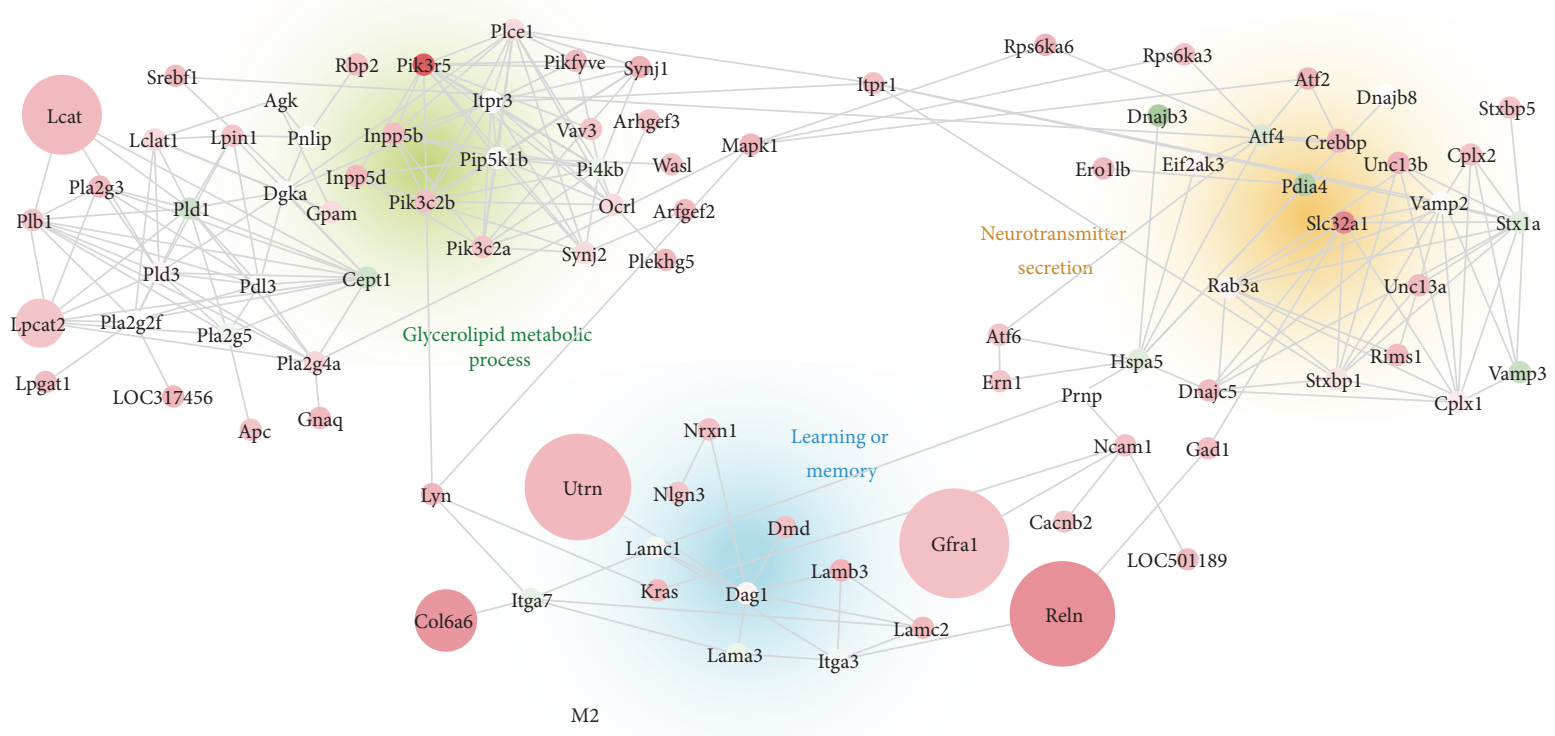

Figure 4: Molecular networks induced by Wnt3a treatment. Gene composition (nodes) and interactions (edges) are shown for modules M1 (upper right, green background), M2 (middle bottom, light blue background), and M3 (upper right, orange background). Node color represents the observed fold change (FC) upon Wnt3a treatment in a gradient from green (downregulation) to red (upregulation) values (i.e., green, $\mathrm{FC}<1$; red, FC $>1$; white, $\mathrm{FC}=1$ ). Similarly, node size is proportional to the $-\log 10 p$ value assigned to the gene behavior. For each module the main GO category associated is shown: $\mathrm{M} 1=$ glycerolipid metabolism process (GO:0046486), $\mathrm{M} 2=$ learning and memory (GO:0007611), and M3 = neurotransmitter secretion (GO:0007269). Module structure: M1 is composed of 44 genes with 132 interactions; M1 is composed of 25 genes with 32 interactions; and M1 is composed of 30 genes with 62 interactions (see also Supplementary Table 4).

different cell backgrounds (Supplementary Figure 3b), likely due to cell-type specific transcriptional and/or translational mechanisms.

Ultimately the goal of Wnt/ $\beta$-catenin signaling in neuronal cells is to modulate changes in gene expression that are manifested in diverse cellular processes, including neurogenesis, axonal pathfinding, dendritic development, synaptic formation, and plasticity $[39,84]$. These changes are likely accomplished by transcription factors that either interact or are activated downstream of $\beta$-catenin transcriptional complexes. Interestingly, we found that a large proportion (18.1\%, $n=28)$ of $\mathrm{Wnt} / \beta$-catenin targets in hippocampal neurons are genes coding for transcription factors (Figure 1). Indeed, within the top 20 Wnt3a upregulated genes we observed 6 transcription factors: Lef1, Ahr, Gata2, Id2, Msx2, and Sp5, that are target genes or functional partners with components of the signaling cascade and that play a role in synaptic development. For instance TCF/LEF transcription factors are instrumental in Wnt/ $\beta$-catenin target gene expression [85], which include target genes participating in synaptic development and function [79]. Similarly, Ahr participates in the expression and membrane presentation of NMDA receptors [86]. Gata2 overexpression in hippocampal neurons leads to a decrease in synaptic spines density and depressive behavior in rats [87]. Id family genes including Id2 are upregulated in Rett syndrome [88], a neurodevelopmental disorder which features altered synaptic plasticity [89]; Id2 is also asymmetrically expressed in human embryonic brain hemispheres suggesting a role for this transcription factor in cortical specialization [90]. Additionally, several of these proteins also modulate Wnt pathway activation in other tissues [91-94]. While further experimental validation including proteomics and TCF/LEF transcription factor occupancy at a genomewide level (ChIP-seq) is needed to confirm these potential candidates as Wnt $/ \beta$-catenin targets in neuronal and nonneuronal cells, we note that none of the early Wnt3a-upregulated genes seems to be the result of downstream transcription factors or secondary transcriptional waves (Supplementary Figure 3c).

GO analysis results from differential expression data revealed that $\mathrm{Wnt} / \beta$-catenin signaling enhances transcription of genes involved in brain development, particularly forebrain development, stem cell differentiation, and neural precursor cell proliferation (Figure 2). In this regard, a role for $\mathrm{Wnt} / \beta$-catenin components in forebrain development has been clearly established [95] and recently this issue has received considerable attention mainly associated with the onset of autism [96]. Similarly, Wnt signaling is well known for enhancing cell renewal of neural stem cells and is a key modulator of neurogenesis [97]. Notably, Axin2, a classic Wnt target gene [47] and $\beta$-catenin destruction complex scaffold protein [98], has been recently shown to control the switch of intermediate progenitors from proliferative to differentiate status in the developing cerebral cortex [99]. Indeed, enhancing Axin expression in neuronal progenitors leads to an enlarged neocortex, an excess of excitatory synapses and autistic like behaviors [100]. 
Network based approaches have been widely used in the study of neurological diseases where usually the number of genetic markers that exceeds the significance threshold is very small; thus most of the identified markers are neglected [73]. The integration of these below-threshold markers into biologically significant networks has successfully identified novel modules of interaction in multiple sclerosis, Alzheimer's disease, autism, and other disorders $[66,71,96,101]$. Our network analysis of Wnt3a differentially expressed pathways extends the notion that $\mathrm{Wnt} / \beta$-catenin signaling has an essential function in neurotransmitter secretion, learning, and memory (Figure 4, modules M2 and M3). We also found a highly significant module comprising components of glycerolipid metabolism that is differentially expressed in neurons exposed to Wnt3a (module M1). M1 is enriched with several lipid-modifying enzymes families, such as PI(3)Ks, PLAs, PLCs, and PLDs whose products are readily found in synaptic membranes enhancing vesicle docking and release [102]. For instance, PLAs produce arachidonic acid, a precursor which will be further processed by COX2, a known Wnt/ $\beta$-catenin target gene [103], during the generation of several eicosanoids which mediate the inflammatory response [104]. Arachidonic acid released from the postsynaptic terminal is known to potentiate synaptic transmission by inhibiting presynaptic potassium channels [105]. Mutations in PLAs have been described in both Alzheimer's disease and autism [104, 106]. Likewise, the production of phosphatidic acid by PLDs modulates several aspects of $\mathrm{Wnt} / \beta$-catenin signaling in cancer and is recognized as a critical regulator of cell proliferation and tumorigenesis [107].

The M2 subnetwork, involved in learning or memory, is enriched in extracellular matrix components such as integrins and laminins. First, Itga9 (integrin subunit alpha 9) is among the 10 top upregulated genes reported in this study. Integrins are differentially expressed in specific regions in the adult brain [108] and they interact with Reln (Reelin) to activate cortical lamination [109]. Interestingly, the Reelin pathway, which crosstalks with Wnt/ $\beta$-catenin signaling throughout brain development [110], has been associated with Alzheimer's disease [111] and autism [112]. Second, the enrichment of laminin subunits is particularly interesting since laminins are necessary for synaptic ultrastructure [113] and have been proven to prevent beta amyloid aggregation [114]. Third, neuronal cell adhesion molecules Neuroligin (Nlgn) and Neurexin (Nrxn) are essential for synaptic structure and function in the synaptic cleft and Nlgn3 and Nrxn1 have been associated with autism [115]. Finally, Wnt3a-derived data also allowed the identification of M3 subnetwork related to neurotransmitter secretion enriched with transcription factors belonging to the ATF/cAMP response element binding proteins (CREB) family of proteins, whose function is involved in synaptic plasticity and memory [116, 117]. Similarly, M3 includes several genes whose products are involved in membrane fusion, synaptic exocytosis, and presynaptic dynamics [118], including SNARES (Vamp2, Vamp3, and Stx1A), STX binding proteins (Stxbp1 and Stxbp5), and Rab signaling molecules (Rab3a and Rims1), which may account for synaptic effects induced by the crosstalk between canonical Wnt pathway and calcium signaling components and that may be important in synaptic dysfunction disorders.

\section{Conclusion}

Transcriptomics and network analyses are highly useful for identifying novel targets that can be used to better understand cellular changes during the onset or progression of neurodegenerative and neurodevelopmental disorders. Our results provide novel insights into the early transcriptional program and molecular networking directed by $\mathrm{Wnt} / \beta$ catenin signaling in hippocampal neurons and warrant further investigation.

\section{Ethical Approval}

All procedures involving experimentation on animals were approved by the Bioethical Committee of Universidad Andres Bello and were conducted in accordance with the guidelines of the National Fund for Scientific and Technological Research (FONDECYT; Chile).

\section{Disclosure}

Current address of Miguel E. Ávila is Instituto de Ciencias Naturales, Universidad de las Américas, Santiago, Chile.

\section{Competing Interests}

The authors declare no conflict of interests.

\section{Authors' Contributions}

Eduardo Pérez-Palma, Víctor Andrade, Giorgia D. Ugarte, and Giancarlo V. De Ferrari conceived and designed the experiments. Eduardo Pérez-Palma, Víctor Andrade, Bernabé I. Bustos, Camilo Villaman, Matías A. Medina, Miguel E. Ávila, and Giorgia D. Ugarte performed experiments or analyzed the data. Eduardo Pérez-Palma, Víctor Andrade, Mario O. Caracci, and Giancarlo V. De Ferrari wrote the paper. All authors read and approved the final manuscript. Eduardo Pérez-Palma and Víctor Andrade contributed equally to this work.

\section{Acknowledgments}

This study was supported by CONICYT regular FONDECYT 1140353 grant to Giancarlo V. De Ferrari.

\section{References}

[1] R. T. Moon, A. D. Kohn, G. V. De Ferrari, and A. Kaykas, "WNT and $\beta$-catenin signalling: diseases and therapies," Nature Reviews Genetics, vol. 5, no. 9, pp. 691-701, 2004.

[2] F. J. T. Staal, T. C. Luis, and M. M. Tiemessen, "WNT signalling in the immune system: WNT is spreading its wings," Nature Reviews Immunology, vol. 8, no. 8, pp. 581-593, 2008. 
[3] H. Clevers and R. Nusse, "Wnt/ $\beta$-catenin signaling and disease," Cell, vol. 149, no. 6, pp. 1192-1205, 2012.

[4] X. He, M. Semenov, K. Tamai, and X. Zeng, "LDL receptorrelated proteins 5 and 6 in Wnt/ $\beta$-catenin signaling: arrows point the way," Development, vol. 131, no. 8, pp. 1663-1677, 2004.

[5] T. V. Lipina, O. Kaidanovich-Beilin, S. Patel et al., "Genetic and pharmacological evidence for schizophrenia-related Disc1 interaction with GSK-3," Synapse, vol. 65, no. 3, pp. 234-248, 2011.

[6] M. J. Hart, R. De Los Santos, I. N. Albert, B. Rubinfeld, and P. Polakis, "Downregulation of $\beta$-catenin by human Axin and its association with the APC tumor suppressor, $\beta$-catenin and GSK3 $\beta$," Current Biology, vol. 8, no. 10, pp. 573-581, 1998.

[7] H. Aberle, A. Bauer, J. Stappert, A. Kispert, and R. Kemler, " $\beta$-Catenin is a target for the ubiquitin-proteasome pathway," The EMBO Journal, vol. 16, no. 13, pp. 3797-3804, 1997.

[8] E. A. Grove, S. Tole, J. Limon, L.-W. Yip, and C. W. Ragsdale, "The hem of the embryonic cerebral cortex is defined by the expression of multiple Wnt genes and is compromised in Gli3deficient mice," Development, vol. 125, no. 12, pp. 2315-2325, 1998.

[9] C. Houart, L. Caneparo, C.-P. Heisenberg, K. A. Barth, M. TakeUchi, and S. W. Wilson, "Establishment of the telencephalon during gastrulation by local antagonism of Wnt signaling," Neuron, vol. 35, no. 2, pp. 255-265, 2002.

[10] S. Maretto, M. Cordenonsi, S. Dupont et al., "Mapping Wnt/ $\beta$ catenin signaling during mouse development and in colorectal tumors," Proceedings of the National Academy of Sciences of the United States of America, vol. 100, no. 6, pp. 3299-3304, 2003.

[11] C.-J. Zhou, C. Zhao, and S. J. Pleasure, "Wnt signaling mutants have decreased dentate granule cell production and radial glial scaffolding abnormalities," Journal of Neuroscience, vol. 24, no. 1, pp. 121-126, 2004.

[12] D.-C. Lie, S. A. Colamarino, H.-J. Song et al., "Wnt signalling regulates adult hippocampal neurogenesis," Nature, vol. 437, no. 7063, pp. 1370-1375, 2005.

[13] E. R. Hollis and Y. Zou, "Expression of the Wnt signaling system in central nervous system axon guidance and regeneration," Frontiers in Molecular Neuroscience, vol. 5, no. 5, 2012.

[14] M. Takeichi and K. Abe, "Synaptic contact dynamics controlled by cadherin and catenins," Trends in Cell Biology, vol. 15, no. 4, pp. 216-221, 2005.

[15] G. V. De Ferrari and and N. C. Inestrosa, "Wnt signaling function in Alzheimer's disease," Brain Research Reviews, vol. 33, no. 1, pp. 1-12, 2000.

[16] G. V. De Ferrari and R. T. Moon, "The ups and downs of Wnt signaling in prevalent neurological disorders," Oncogene, vol. 25, no. 57, pp. 7545-7553, 2006.

[17] A. Ahmad-Annuar, L. Ciani, I. Simeonidis et al., "Signaling across the synapse: a role for Wnt and Dishevelled in presynaptic assembly and neurotransmitter release," Journal of Cell Biology, vol. 174, no. 1, pp. 127-139, 2006.

[18] N. C. Inestrosa and E. Arenas, "Emerging roles of Wnts in the adult nervous system," Nature Reviews Neuroscience, vol. 11, no. 2, pp. 77-86, 2010.

[19] L. Ciani, K. A. Boyle, E. Dickins et al., "Wnt7a signaling promotes dendritic spine growth and synaptic strength through Ca 2+/Calmodulin-dependent protein kinase II," Proceedings of the National Academy of Sciences of the United States of America, vol. 108, no. 26, pp. 10732-10737, 2011.
[20] G. V. De Ferrari, M. E. Avila, M. A. Medina, E. Pérez-Palma, B. I. Bustos, and M. A. Alarcón, "Wnt/ $\beta$-catenin signaling in Alzheimer's disease," CNS \& Neurological Disorders-Drug Targets, vol. 13, no. 5, pp. 745-754, 2014.

[21] N. Itasaki, C. M. Jones, S. Mercurio et al., "Wise, a contextdependent activator and inhibitor of Wnt signalling," Development, vol. 130, no. 18, pp. 4295-4305, 2003.

[22] A. Caricasole, T. Ferraro, L. Iacovelli et al., "Functional characterization of WNT7A signaling in PC12 cells: interaction with a FZD5•LRP6 receptor complex and modulation by Dickkopf proteins," The Journal of Biological Chemistry, vol. 278, no. 39, pp. 37024-37031, 2003.

[23] S. M. K. Lee, S. Tole, E. Grove, and A. P. McMahon, "A local Wnt-3a signal is required for development of the mammalian hippocampus," Development, vol. 127, no. 3, pp. 457-467, 2000.

[24] J. Chen, C. S. Park, and S.-J. Tang, "Activity-dependent synaptic Wnt release regulates hippocampal long term potentiation," Journal of Biological Chemistry, vol. 281, no. 17, pp. 11910-11916, 2006.

[25] K. Sharma, S.-Y. Choi, Y. Zhang et al., "High-throughput genetic screen for synaptogenic factors: identification of lrp6 as critical for excitatory synapse development," Cell Reports, vol. 5, no. 5, pp. 1330-1341, 2013.

[26] W. Cerpa, J. A. Godoy, I. Alfaro et al., "Wnt-7a modulates the synaptic vesicle cycle and synaptic transmission in hippocampal neurons," Journal of Biological Chemistry, vol. 283, no. 9, pp. 5918-5927, 2008.

[27] A. C. Hall, F. R. Lucas, and P. C. Salinas, "Axonal remodeling and synaptic differentiation in the cerebellum is regulated by WNT-7a signaling," Cell, vol. 100, no. 5, pp. 525-535, 2000.

[28] M. E. Avila, F. J. Sepúlveda, C. F. Burgos et al., "Canonical Wnt3a modulates intracellular calcium and enhances excitatory neurotransmission in hippocampal neurons," The Journal of Biological Chemistry, vol. 285, no. 24, pp. 18939-18947, 2010.

[29] S. Kishida, K. Hamao, M. Inoue et al., "Dvl regulates endo- and exocytotic processes through binding to synaptotagmin," Genes to Cells, vol. 12, no. 1, pp. 49-61, 2007.

[30] L. Varela-Nallar, I. E. Alfaro, F. G. Serrano, J. Parodi, and N. C. Inestrosa, "Wingless-type family member 5A (Wnt-5a) stimulates synaptic differentiation and function of glutamatergic synapses," Proceedings of the National Academy of Sciences of the United States of America, vol. 107, no. 49, pp. 21164-21169, 2010.

[31] W. Cerpa, A. Gambrill, N. C. Inestrosa, and A. Barria, "Regulation of NMDA-receptor synaptic transmission by Wnt signaling," Journal of Neuroscience, vol. 31, no. 26, pp. 9466-9471, 2011.

[32] M. Simonetti, N. Agarwal, S. Stösser et al., "Wnt-fzd signaling sensitizes peripheral sensory neurons via distinct noncanonical pathways," Neuron, vol. 83, no. 1, pp. 104-121, 2014.

[33] S. X. Bamji, K. Shimazu, N. Kimes et al., "Role of $\beta$-catenin in synaptic vesicle localization and presynaptic assembly," Neuron, vol. 40, no. 4, pp. 719-731, 2003.

[34] Y. Iwai, Y. Hirota, K. Ozaki, H. Okano, M. Takeichi, and T. Uemura, "DN-cadherin is required for spatial arrangement of nerve terminals and ultrastructural organization of synapses," Molecular and Cellular Neuroscience, vol. 19, no. 3, pp. 375-388, 2002.

[35] K. Jüngling, V. Eulenburg, R. Moore, R. Kemler, V. Lessmann, and K. Gottmann, "N-cadherin transsynaptically regulates short-term plasticity at glutamatergic synapses in embryonic stem cell-derived neurons," The Journal of Neuroscience, vol. 26, no. 26, pp. 6968-6978, 2006. 
[36] Y. Sun, M. Aiga, E. Yoshida, P. O. Humbert, and S. X. Bamji, "Scribble interacts with $\beta$-catenin to localize synaptic vesicles to synapses," Molecular Biology of the Cell, vol. 20, no. 14, pp. 3390-3400, 2009.

[37] H. Togashi, K. Abe, A. Mizoguchi, K. Takaoka, O. Chisaka, and M. Takeichi, "Cadherin regulates dendritic spine morphogenesis," Neuron, vol. 35, no. 1, pp. 77-89, 2002.

[38] C. A. Oliva, J. Y. Vargas, and N. C. Inestrosa, "Wnt signaling: role in LTP, neural networks and memory," Ageing Research Reviews, vol. 12, no. 3, pp. 786-800, 2013.

[39] P. C. Salinas, "Wnt signaling in the vertebrate central nervous system: from axon guidance to synaptic function," Cold Spring Harbor Perspectives in Biology, vol. 4, no. 2, 2012.

[40] T. S. Gujral and G. MacBeath, "A system-wide investigation of the dynamics of Wnt signaling reveals novel phases of transcriptional regulation," PLOS ONE, vol. 5, no. 4, Article ID e10024, 2010.

[41] E. M. Wexler, E. Rosen, D. Lu et al., "Genome-wide analysis of a Wntl-regulated transcriptional network implicates neurodegenerative pathways," Science Signaling, vol. 4, no. 193, article ra65, 2011.

[42] F. Nuñez, S. Bravo, F. Cruzat, M. Montecino, G. V. De Ferrari, and $\mathrm{M}$. Campbell, "Wnt/ $\beta$-catenin signaling enhances cyclooxygenase-2 (COX2) Transcriptional activity in gastric cancer cells," PLoS ONE, vol. 6, no. 4, Article ID e18562, 2011.

[43] G. D. Ugarte, M. F. Vargas, M. A. Medina et al., "Wnt signaling induces transcription, spatial proximity, and translocation of fusion gene partners in human hematopoietic cells," Blood, vol. 126, no. 15, pp. 1785-1789, 2015.

[44] M. A. Medina, G. D. Ugarte, M. F. Vargas et al., "Alternative RUNX1 promoter regulation by $\mathrm{Wnt} / \beta$-catenin signaling in leukemia cells and human hematopoietic progenitors," Journal of Cellular Physiology, vol. 231, no. 7, pp. 1460-1467, 2016.

[45] M. V. Chang, J. L. Chang, A. Gangopadhyay, A. Shearer, and K. M. Cadigan, "Activation of wingless targets requires bipartite recognition of DNA by TCF," Current Biology, vol. 18, no. 23, pp. 1877-1881, 2008.

[46] K. Hovanes, T. W. H. Li, J. E. Munguia et al., " $\beta$-Cateninsensitive isoforms of lymphoid enhancer factor- 1 are selectively expressed in colon cancer," Nature Genetics, vol. 28, no. 1, pp. 53-57, 2001.

[47] E.-H. Jho, T. Zhang, C. Domon, C.-K. Joo, J.-N. Freund, and F. Costantini, "Wnt/ $\beta$-catenin/Tcf signaling induces the transcription of Axin2, a negative regulator of the signaling pathway," Molecular and Cellular Biology, vol. 22, no. 4, pp.1172$1183,2002$.

[48] Y. Kawasaki, F. Kugimiya, H. Chikuda et al., "Phosphorylation of GSK-3 $\beta$ by cGMP-dependent protein kinase II promotes hypertrophic differentiation of murine chondrocytes," Journal of Clinical Investigation, vol. 118, no. 7, pp. 2506-2515, 2008.

[49] S. Segditsas, O. Sieber, M. Deheragoda et al., "Putative direct and indirect Wnt targets identified through consistent gene expression changes in APC-mutant intestinal adenomas from humans and mice," Human Molecular Genetics, vol. 17, no. 24, pp. 3864-3875, 2008.

[50] S. Gerbal-Chaloin, A.-S. Dumé, P. Briolotti et al., "The WNT/ $\beta$ catenin pathway is a transcriptional regulator of CYP2E1, CYP1A2, and aryl hydrocarbon receptor gene expression in primary human hepatocytes," Molecular Pharmacology, vol. 86, no. 6, pp. 624-634, 2014.

[51] L. Buttitta, T. S. Tanaka, A. E. Chen, M. S. H. Ko, and C.-M. Fan, "Microarray analysis of somitogenesis reveals novel targets of different WNT signaling pathways in the somitic mesoderm," Developmental Biology, vol. 258, no. 1, pp. 91-104, 2003.

[52] B. Gustafson and U. Smith, "Activation of canonical winglesstype MMTV integration site family (Wnt) signaling in mature adipocytes increases $\beta$-catenin levels and leads to cell dedifferentiation and insulin resistance," The Journal of Biological Chemistry, vol. 285, no. 18, pp. 14031-14041, 2010.

[53] S. P. Rockman, S. A. Currie, M. Ciavarella et al., "Id2 is a target of the $\beta$-catenin/T cell factor pathway in colon carcinoma," Journal of Biological Chemistry, vol. 276, no. 48, pp. 45113-45119, 2001.

[54] Y. Zhai, A. Iura, S. Yeasmin et al., "MSX2 is an oncogenic downstream target of activated WNT signaling in ovarian endometrioid adenocarcinoma," Oncogene, vol. 30, no. 40, pp. 4152-4162, 2011.

[55] N. Fujimura, T. Vacik, O. Machon et al., "Wnt-mediated downregulation of Sp1 target genes by a transcriptional repressor Sp5," Journal of Biological Chemistry, vol. 282, no. 2, pp. 1225-1237, 2007.

[56] K. R. Reed, I. V. Korobko, N. Ninkina et al., "Hunk/Mak-v is a negative regulator of intestinal cell proliferation," BMC Cancer, vol. 15, no. 1, article no. 110, 2015.

[57] S. Kishida, H. Yamamoto, and A. Kikuchi, "Wnt-3a and Dvl induce neurite retraction by activating rho-associated kinase," Molecular and Cellular Biology, vol. 24, no. 10, pp. 4487-4501, 2004.

[58] K. Willert, J. D. Brown, E. Danenberg et al., "Wnt proteins are lipid-modified and can act as stem cell growth factors," Nature, vol. 423, no. 6938, pp. 448-452, 2003.

[59] C. A. Schneider, W. S. Rasband, and K. W. Eliceiri, "NIH Image to ImageJ: 25 years of image analysis," Nature Methods, vol. 9, no. 7, pp. 671-675, 2012.

[60] W. Huber, V. J. Carey, R. Gentleman et al., "Orchestrating high-throughput genomic analysis with Bioconductor," Nature Methods, vol. 12, no. 2, pp. 115-121, 2015.

[61] S. Anders and W. Huber, "Differential expression analysis for sequence count data," Genome Biology, vol. 11, no. 10, article R106, 2010.

[62] E. P. Consortium, "An integrated encyclopedia of DNA elements in the human genome," Nature, vol. 489, no. 7414, pp. 57-74, 2012.

[63] Gene Ontology Consortium, "The Gene Ontology (GO) database and informatics resource," Nucleic Acids Research, vol. 32, pp. D258-D261, 2004.

[64] S. Grossmann, S. Bauer, P. N. Robinson, and M. Vingron, "Improved detection of overrepresentation of Gene-Ontology annotations with parent-child analysis," Bioinformatics, vol. 23, no. 22, pp. 3024-3031, 2007.

[65] D. Warde-Farley, S. L. Donaldson, O. Comes et al., "The GeneMANIA prediction server: biological network integration for gene prioritization and predicting gene function," Nucleic Acids Research, vol. 38, pp. W214-W220, 2010.

[66] E. Pérez-Palma, B. I. Bustos, C. F. Villamán et al., "Overrepresentation of glutamate signaling in Alzheimer's disease: network-based pathway enrichment using meta-analysis of genome-wide association studies," PLoS ONE, vol. 9, no. 4, Article ID e95413, 2014.

[67] P. H. Westfall and S. S. Young, Resampling-Based Multiple Testing: Examples and Methods for p-Value Adjustment, WileyInterscience, 1993.

[68] D. Szklarczyk, A. Franceschini, M. Kuhn et al., “The STRING database in 2011: functional interaction networks of proteins, 
globally integrated and scored," Nucleic Acids Research, vol. 39, supplement 1, pp. D561-D568, 2010.

[69] M. S. Cline, M. Smoot, E. Cerami et al., "Integration of biological networks and gene expression data using Cytoscape," Nature Protocols, vol. 2, no. 10, pp. 2366-2382, 2007.

[70] T. Ideker, O. Ozier, B. Schwikowski, and A. F. Siegel, "Discovering regulatory and signalling circuits in molecular interaction networks," Bioinformatics, vol. 18, supplement 1, pp. S233-S240, 2002.

[71] S. E. Baranzini, N. W. Galwey, J. Wang et al., "Pathway and network-based analysis of genome-wide association studies in multiple sclerosis," Human Molecular Genetics, vol. 18, no. 11, pp. 2078-2090, 2009.

[72] S. E. Baranzini, N. W. Galwey, J. Wang et al., "Pathway and network-based analysis of genome-wide association studies in multiple sclerosis," Human Molecular Genetics, vol. 18, no. 11, pp. 2078-2090, 2009.

[73] N. N. Parikshak, M. J. Gandal, and D. H. Geschwind, "Systems biology and gene networks in neurodevelopmental and neurodegenerative disorders," Nature Reviews Genetics, vol. 16, no. 8, pp. 441-458, 2015.

[74] J. Willert, M. Epping, J. R. Pollack, P. O. Brown, and R. Nusse, "The role of serine proteases and serine protease inhibitors in the migration of gonadotropin-releasing hormone neurons," BMC Developmental Biology, vol. 2, article no. 1, pp. 1-7, 2002.

[75] L. Taneyhill and D. Pennica, "Identification of Wnt responsive genes using a murine mammary epithelial cell line model system," BMC Developmental Biology, vol. 4, article no. 1, 2004.

[76] P. Hatzis, L. G. Van Der Flier, M. A. Van Driel et al., "Genomewide pattern of TCF7L2/TCF4 chromatin occupancy in colorectal cancer cells," Molecular and Cellular Biology, vol. 28, no. 8, pp. 2732-2744, 2008.

[77] M. S. Arrázola, L. Varela-Nallar, M. Colombres et al., "Calcium/calmodulin-dependent protein kinase type IV is a target gene of the $\mathrm{Wnt} / \beta$-catenin signaling pathway," Journal of Cellular Physiology, vol. 221, no. 3, pp. 658-667, 2009.

[78] C. Hödar, R. Assar, M. Colombres et al., "Genome-wide identification of new Wnt/ $\beta$-catenin target genes in the human genome using CART method," BMC Genomics, vol. 11, no. 1, article 348 , 2010.

[79] M. B. Wisniewska, A. Nagalski, M. Dabrowski, K. Misztal, and J. Kuznicki, "Novel $\beta$-catenin target genes identified in thalamic neurons encode modulators of neuronal excitability," BMC Genomics, vol. 13, no. 1, article 635, 2012.

[80] G. V. De Ferrari and R. T. Moon, “The ups and downs of Wnt signaling in prevalent neurological disorders," Oncogene, vol. 25, no. 57, pp. 7545-7553, 2006.

[81] M. O. Caracci, M. E. Ávila, and G. V. De Ferrari, "Synaptic Wnt/GSK3 $\beta$ signaling hub in autism," Neural Plasticity, vol. 2016, Article ID 9603751, 10 pages, 2016.

[82] G. V. De Ferrari, M. E. Avila, M. A. Medina, E. Pérez-Palma, B. I. Bustos, and M. A. Alarcón, "Wnt/ $\beta$-catenin signaling in Alzheimer's disease," Formerly Current Drug Targets-CNS \& Neurological Disorders, vol. 13, no. 5, pp. 745-754, 2014.

[83] C. Huang, X.-H. Fu, D. Zhou, and J.-M. Li, "The role of Wnt $/ \beta$-catenin signaling pathway in disrupted hippocampal neurogenesis of temporal lobe epilepsy: a potential therapeutic target?" Neurochemical Research, vol. 40, no. 7, pp. 1319-1332, 2015.

[84] N. C. Inestrosa and L. Varela-Nallar, "Wnt signaling in the nervous system and in Alzheimer's disease," Journal of Molecular Cell Biology, vol. 6, no. 1, pp. 64-74, 2014.
[85] K. M. Cadigan and M. L. Waterman, "TCF/LEFs and Wnt signaling in the nucleus," Cold Spring Harbor Perspectives in Biology, vol. 4, no. 11, Article ID a007906, 2012.

[86] C.-H. Lin, C.-C. Chen, C.-M. Chou et al., "Knockdown of the aryl hydrocarbon receptor attenuates excitotoxicity and enhances NMDA-induced BDNF expression in cortical neurons," Journal of Neurochemistry, vol. 111, no. 3, pp. 777-789, 2009.

[87] M. Choi, S. E. Wang, S. Y. Ko et al., "Overexpression of human GATA-1 and GATA-2 interferes with spine formation and produces depressive behavior in rats," PLOS ONE, vol. 9, no. 10, Article ID e109253, 2014.

[88] S. Peddada, D. H. Yasui, and J. M. LaSalle, "Inhibitors of differentiation (ID1, ID2, ID3 and ID4) genes are neuronal targets of MeCP2 that are elevated in Rett syndrome," Human Molecular Genetics, vol. 15, no. 12, pp. 2003-2014, 2006.

[89] S.-M. Weng, F. McLeod, M. E. S. Bailey, and S. R. Cobb, "Synaptic plasticity deficits in an experimental model of rett syndrome: long-term potentiation saturation and its pharmacological reversal," Neuroscience, vol. 180, pp. 314-321, 2011.

[90] T. Sun, C. Patoine, A. Abu-Khalil et al., "Early asymmetry of gene transcription in embryonic human left and right cerebral cortex," Science, vol. 308, no. 5729, pp. 1794-1798, 2005.

[91] G. Weidinger, C. J. Thorpe, K. Wuennenberg-Stapleton, J. Ngai, and R. T. Moon, "The Spl-related transcription factors $s p 5$ and sp5-like act downstream of $\mathrm{Wnt} / \beta$-catenin signaling in mesoderm and neuroectoderm patterning," Current Biology, vol. 15, no. 6, pp. 489-500, 2005.

[92] J. Procházková, M. Kabátková, V. Bryja et al., “The interplay of the aryl hydrocarbon receptor and $\beta$-catenin alters both AhRdependent transcription and wnt $/ \beta$-catenin signaling in liver progenitors," Toxicological Sciences, vol. 122, no. 2, pp. 349-360, 2011.

[93] M. S. Mimoto, S. Kwon, Y. S. Green, D. Goldman, and J. L. Christian, "GATA2 regulates Wnt signaling to promote primitive red blood cell fate," Developmental Biology, vol. 407, no. 1, pp. 1-11, 2015.

[94] H.-J. Dong, G.-B. Jang, H.-Y. Lee et al., "The Wnt/ $\beta$-catenin signaling/Id 2 cascade mediates the effects of hypoxia on the hierarchy of colorectal-cancer stem cells," Scientific Reports, vol. 6, Article ID 22966, 2016.

[95] S. J. Harrison-Uy and S. J. Pleasure, "Wnt signaling and forebrain development," Cold Spring Harbor Perspectives in Biology, vol. 4, no. 7, Article ID a008094, 2012.

[96] N. Krumm, B. J. O’Roak, J. Shendure, and E. E. Eichler, "A de novo convergence of autism genetics and molecular neuroscience," Trends in Neurosciences, vol. 37, no. 2, pp. 95-105, 2014.

[97] M. Y. S. Kalani, S. H. Cheshier, B. J. Cord et al., "Wnt-mediated self-renewal of neural stem/progenitor cells," Proceedings of the National Academy of Sciences of the United States of America, vol. 105, no. 44, pp. 16970-16975, 2008.

[98] A. Kikuchi, "Roles of axin in the Wnt signalling pathway," Cellular Signalling, vol. 11, no. 11, pp. 777-788, 1999.

[99] W.-Q. Fang, W.-W. Chen, A. Y. Fu, and N. Ip, "Axin directs the amplification and differentiation of intermediate progenitors in the developing cerebral cortex," Neuron, vol. 79, no. 4, pp. 665679, 2013.

[100] W.-Q. Fang, W.-W. Chen, L. Jiang et al., "Overproduction of upper-layer neurons in the neocortex leads to autism-like features in mice," Cell Reports, vol. 9, no. 5, pp. 1635-1643, 2014. 
[101] M. R. Johnson, K. Shkura, S. R. Langley et al., "Systems genetics identifies a convergent gene network for cognition and neurodevelopmental disease," Nature Neuroscience, vol. 19, no. 2, pp. 223-232, 2016.

[102] J. Rohrbough and K. Broadie, "Lipid regulation of the synaptic vesicle cycle," Nature Reviews Neuroscience, vol. 6, no. 2, pp.139150, 2005.

[103] F. Nuñez, S. Bravo, F. Cruzat, M. Montecino, and G. V. de Ferrari, "Wnt $/ \beta$-catenin signaling enhances cyclooxygenase-2 (COX2) transcriptional activity in gastric cancer cells," PLoS ONE, vol. 6, no. 4, Article ID e18562, 2011.

[104] J. Tamiji and D. A. Crawford, "The neurobiology of lipid metabolism in autism spectrum disorders," NeuroSignals, vol. 18, no. 2, pp. 98-112, 2011.

[105] M. Carta, F. Lanore, N. Rebola et al., "Membrane lipids tune synaptic transmission by direct modulation of presynaptic potassium channels," Neuron, vol. 81, no. 4, pp. 787-799, 2014.

[106] R. O. Sanchez-Mejia and L. Mucke, "Phospholipase $A_{2}$ and arachidonic acid in Alzheimer's disease," Biochimica et Biophysica Acta-Molecular and Cell Biology of Lipids, vol. 1801, no. 8, pp. 784-790, 2010.

[107] D. W. Kang, K.-Y. Choi, and D. S. Min, "Phospholipase D meets Wnt signaling: a new target for cancer therapy," Cancer Research, vol. 71, no. 2, pp. 293-297, 2011.

[108] J. K. Pinkstaff, J. Detterich, G. Lynch, and C. Gall, "Integrin subunit gene expression is regionally differentiated in adult brain," The Journal of Neuroscience, vol. 19, no. 5, pp. 1541-1556, 1999.

[109] L. Dulabon, E. C. Olson, M. G. Taglienti et al., "Reelin binds $\alpha 3 \beta 1$ integrin and inhibits neuronal migration," Neuron, vol. 27, no. 1, pp. 33-44, 2000.

[110] O. Reiner and T. Sapir, "Similarities and differences between the Wnt and reelin pathways in the forming brain," Molecular Neurobiology, vol. 31, no. 1-3, pp. 117-134, 2005.

[111] J. Herz and Y. Chen, "Reelin, lipoprotein receptors and synaptic plasticity," Nature Reviews Neuroscience, vol. 7, no. 11, pp. 850859, 2006.

[112] H. Zhang, X. Liu, C. Zhang et al., "Reelin gene alleles and susceptibility to autism spectrum disorders," Molecular Psychiatry, vol. 7, no. 9, pp. 1012-1017, 2002.

[113] C. Egles, T. Claudepierre, M. K. Manglapus, M.-F. Champliaud, W. J. Brunken, and D. D. Hunter, "Laminins containing the $\beta 2$ chain modulate the precise organization of CNS synapses," Molecular and Cellular Neuroscience, vol. 34, no. 3, pp. 288-298, 2007.

[114] C. Morgan and N. C. Inestrosa, "Interactions of laminin with the amyloid $\beta$ peptide. Implications for Alzheimer's disease," Brazilian Journal of Medical and Biological Research, vol. 34, no. 5, pp. 597-601, 2001.

[115] T. C. Südhof, "Neuroligins and neurexins link synaptic function to cognitive disease," Nature, vol. 455, no. 7215, pp. 903-911, 2008.

[116] J. Li, C. Sutter, D. S. Parker, T. Blauwkamp, M. Fang, and K. M. Cadigan, "CBP/p300 are bimodal regulators of Wnt signaling," The EMBO Journal, vol. 26, no. 9, pp. 2284-2294, 2007.

[117] S. Pasini, C. Corona, J. Liu, L. A. Greene, and M. L. Shelanski, "Specific downregulation of hippocampal ATF4 reveals a necessary role in synaptic plasticity and memory," Cell Reports, vol. 11, no. 2, pp. 183-191, 2015.

[118] T. C. Sudhof and J. Rizo, "Synaptic vesicle exocytosis," Cold Spring Harbor Perspectives in Biology, vol. 3, no. 12, Article ID a005637, 2011. 

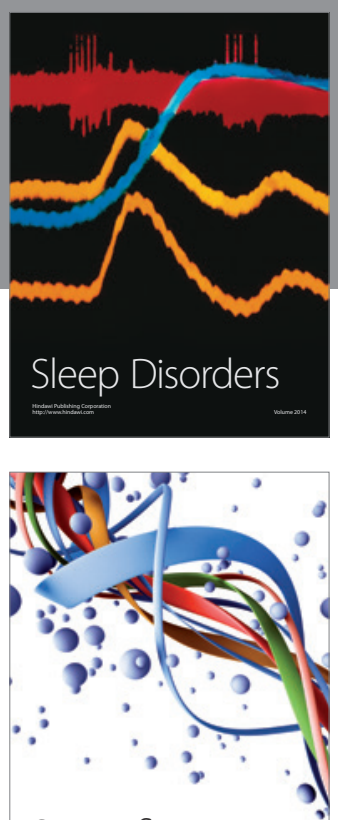

Scientifica
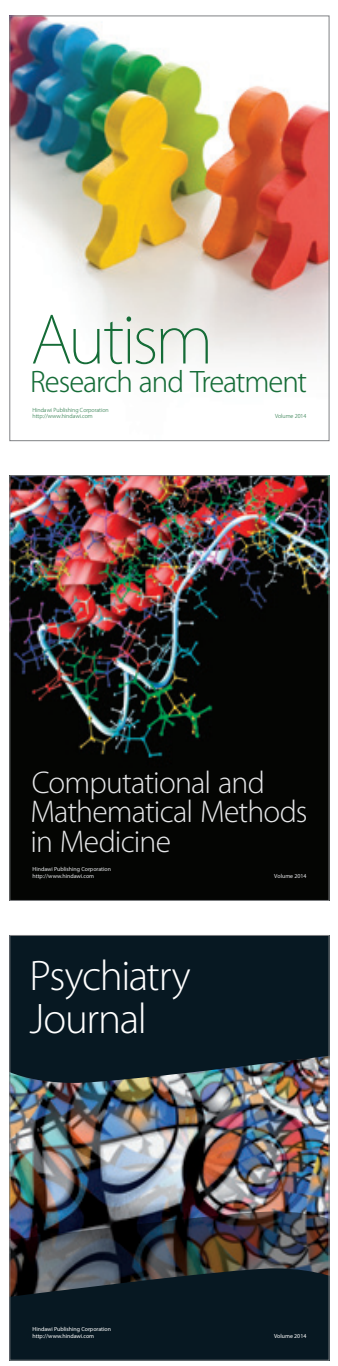
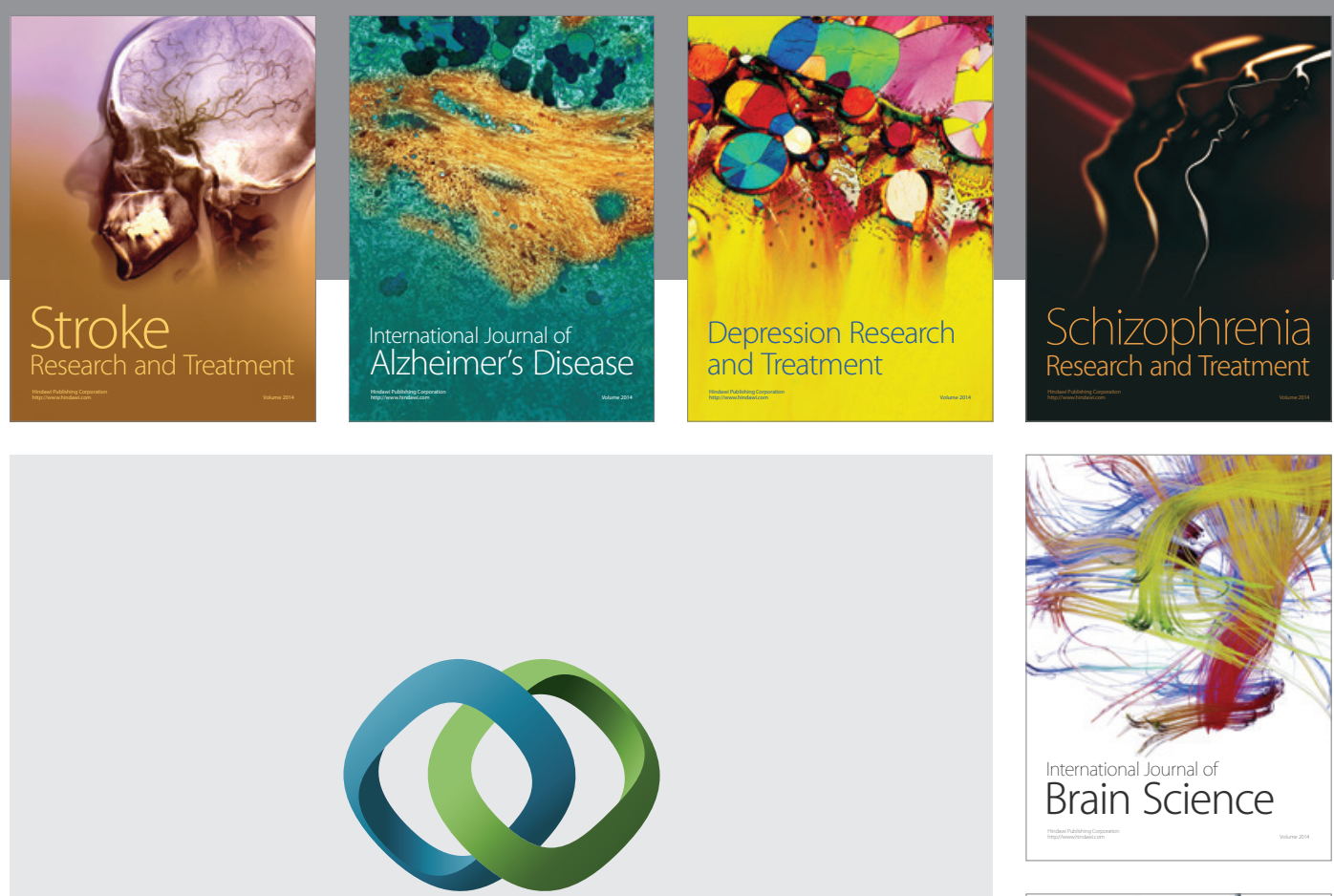

\section{Hindawi}

Submit your manuscripts at

http://www.hindawi.com
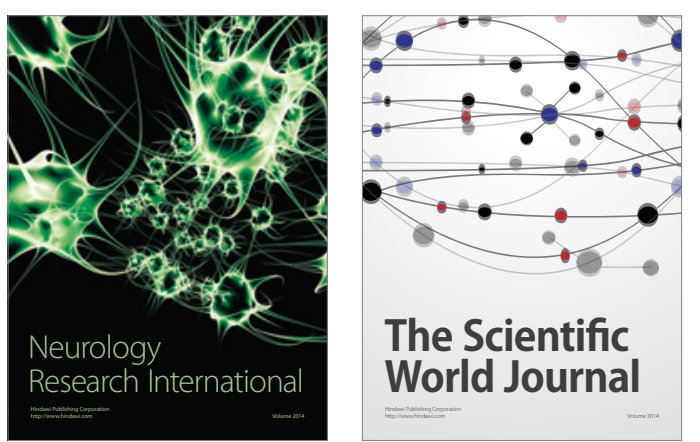

The Scientific World Journal

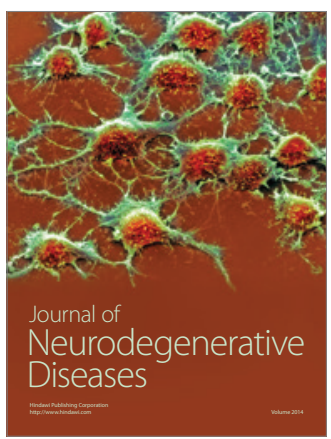

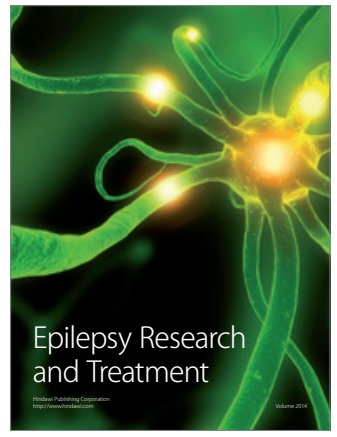

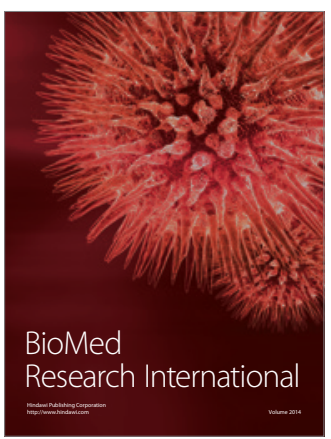

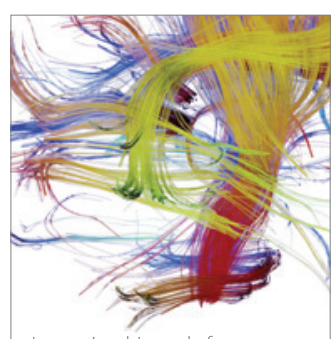

Brain Science

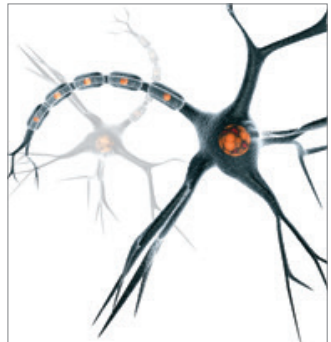

Neural Plasticity
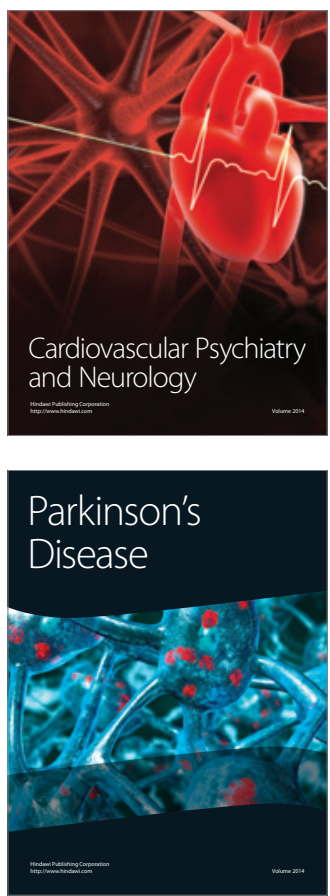